Article

\title{
Sociodemographic and Clinical Determinants of Multimorbidity of Underlying Conditions That Increase the Risk of Severe Illness from COVID-19 in Chronic Adult Individuals
}

\author{
Filipe Prazeres $1,2,3, * \mathbb{D}$, Luísa Castro ${ }^{3,4,5}$ (D) and Andreia Teixeira ${ }^{3,5,6}$ (D) \\ 1 Faculty of Health Sciences, University of Beira Interior, 6200-506 Covilhã, Portugal \\ 2 Family Health Unit Beira Ria, 3830-596 Gafanha da Nazaré, Portugal \\ 3 Centre for Health Technology and Services Research (CINTESIS), University of Porto, \\ 4200-450 Porto, Portugal; luisacastro@med.up.pt (L.C.); andreiasofiat@med.up.pt (A.T.) \\ 4 School of Health of Polytechnic of Porto, 4200-072 Porto, Portugal \\ 5 MEDCIDS-Department of Community Medicine, Information and Decision in Health, Faculty of Medicine, \\ University of Porto, 4099-002 Porto, Portugal \\ 6 AdiT-LAB, Instituto Politécnico de Viana do Castelo, Rua Escola Industrial e Comercial Nun'Álvares, \\ 4900-347 Viana do lo, Portugal \\ * Correspondence: filipeprazeresmd@gmail.com; Tel.: +351-234-393-150
}

check for updates

Citation: Prazeres, F.; Castro, L.; Teixeira, A. Sociodemographic and Clinical Determinants of Multimorbidity of Underlying Conditions That Increase the Risk of Severe Illness from COVID-19 in Chronic Adult Individuals. BioMed 2022, 2, 94-103. https://doi.org/ 10.3390/biomed2010010

Academic Editor: Wolfgang Graier

Received: 14 January 2022

Accepted: 15 February 2022

Published: 20 February 2022

Publisher's Note: MDPI stays neutral with regard to jurisdictional claims in published maps and institutional affiliations.

Copyright: (c) 2022 by the authors. Licensee MDPI, Basel, Switzerland. This article is an open access article distributed under the terms and conditions of the Creative Commons Attribution (CC BY) license (https:// creativecommons.org/licenses/by/ $4.0 /)$.

\begin{abstract}
Multimorbid patients represent a special population of vulnerable individuals who suffer from two or more long-term conditions. They are a very prevalent group with an increased risk of death from COVID-19. The present study aimed to identify the sociodemographic and clinical determinants of multimorbidity of underlying conditions that increase the risk of severe COVID-19 in chronic adult individuals by analyzing data from the Portuguese National Health Survey 2019. The inclusion sample consisted of 7859 adult residents in Portugal who had at least one chronic condition. The health conditions considered for multimorbidity were CKD, COPD, heart conditions, diabetes mellitus, obesity, and smoking. In Portugal, approximately 6 out of every 10 individuals with chronic diseases suffer from one or more conditions that are on the list of those at increased risk of severe COVID-19 disease, and approximately 2 out of every 10 individuals have multimorbidity. Obesity and diabetes are the most frequent risk factors. Timely interventions (e.g., regular medical follow-up for preventive health services and health information) targeting multimorbidity in males and individuals with low educational levels, a poor health status, and low functionality may help to reduce the risk of severe COVID-19 and post-COVID-19 sequelae, and to improve health in a large proportion of the population.
\end{abstract}

Keywords: multimorbidity; COVID-19; SARS-CoV-2; special population; epidemiology; severity of COVID-19

\section{Introduction}

Since the beginning of the severe acute respiratory syndrome coronavirus 2 (SARSCoV-2) pandemic, coronavirus disease 2019 (COVID-19) has caused at least 4,389,376 deaths worldwide, among more than 209.04 million infections [1]. Portugal has now marked 17,584 deaths from COVID-19, and 1,006,588 cases of infection have been registered since March 2020, according to the Directorate-General of Health [2].

Despite the ongoing efforts of the scientific community to achieve better and more effective treatments for those infected with COVID-19, it has been established that COVID-19 vaccination is efficacious in protecting individuals before exposure to coronavirus and in reducing the spread of the disease [3]. Nonetheless, currently, only $24.3 \%$ of the world population is fully vaccinated, and in low-income countries, an even lower percentage of individuals have received at least one dose $(1.4 \%)[4,5]$. 
Since COVID-19 vaccination still does not reach everyone (not even all people with a compelling indication to be vaccinated), and because there are still some uncertainties regarding the long-term immunity and the protection against new variants [6], the study of individuals at risk of severe adverse outcomes from COVID-19, including hospitalization, admission to an intensive care unit (ICU), intubation or mechanical ventilation, or death [7], continues to be of major importance, in order to prioritize this group for vaccination or to shield them from the rest of the population [8]. More recently, the literature has shown that post-COVID-19 patients can suffer from several sequelae [9], and among those with a previous ICU admission, their quality of life is poorer [10].

The US Centers for Disease Control and Prevention considers that older individuals and those with underlying health conditions are at increased risk of severe COVID-19 [7]. This includes individuals with diabetes, cardiovascular disease (CVD), obesity, and a series of other long-term conditions [11-15].

Multimorbid patients represent a special population of vulnerable individuals who suffer from two or more long-term conditions. They are a very prevalent group, not only in Portugal but worldwide $[16,17]$. Nonetheless, research regarding the risks of COVID-19 for multimorbid people is still scarce $[18,19]$. The literature shows that the risk of death from COVID-19 is increased in multimorbid patients [20], and in those with certain sociodemographic factors, such as non-whites and those who are most socioeconomically deprived [21].

The present study aimed to identify the sociodemographic and clinical determinants of multimorbidity of underlying conditions that increase the risk of severe illness from COVID-19 in chronic adult individuals, by analyzing data from the Portuguese National Health Survey 2019.

\section{Materials and Methods}

\subsection{Study Design and Population}

The 2019 National Health Survey (Portuguese acronym: INS 2019) is a European harmonized and regulated survey (EU Regulation 2018/255), granting the comparison of its results internationally [22]. Between September 2019 and January 2020, this communitybased cross-sectional study was performed throughout the Portuguese territory by Statistics Portugal in collaboration with the National Health Institute Dr. Ricardo Jorge [22]. A nationally representative sample of the population living in Portugal ( $\geq 15$ years of age) was obtained through multistage stratified and cluster sampling of 22,191 households. Data collection methods included face to face, with computer and electronic questionnaires. Further details regarding the 2019 National Health Survey methodology are described elsewhere [23]. Globally, the response rate was $65.9 \%$, with 14,617 valid responses; data concerning health status, healthcare, health determinants, income and health expenses, reproductive health, food consumption, life satisfaction, and long-term disability were collected [22].

For the present analysis, data from the INS 2019 related to adult (18+ years of age) residents in Portugal who had at least one chronic condition were included in the study ( $n=7859$, after excluding 380 participants with data missing on the determinants of interest). Having a chronic condition was defined by an affirmative response to the question "Do you have a chronic illness or long-term health problem? (lasts or may last longer than 6 months)".

The present study was reviewed and approved by the Ethics Committee of the University of Beira Interior on October 13th 2020 (code number CE-UBI-Pj-2020-073) and abided by the Declaration of Helsinki ethical standards. Data from the INS 2019 were analyzed, and no other information was collected. Informed consent was obtained from all INS 2019 participants. The anonymity of the participants and the confidentiality of the data in the INS 2019 database were assured. Data was accessed on November 2020. 


\subsection{Study Variables and Measures}

Multimorbidity of underlying conditions that increase the risk of severe COVID-19 was defined by the presence in the same individual of two or more of the following conditions: chronic kidney disease (CKD), chronic obstructive pulmonary disease (COPD), heart conditions, diabetes mellitus, obesity, and smoking. These conditions were selected because they had the strongest and most consistent scientific evidence of increasing the risk of severe illness from COVID-19 in adults of any age, according to the US Centers for Disease Control and Prevention's (CDC) list of those at increased risk of severe COVID-19 disease, updated as of 2 November 2020 [7].

The presence of CKD was assessed by a positive response to the question "Please indicate whether during the past 12 months you have had chronic kidney problems, including kidney failure?"; COPD was evaluated by a positive response to the question "Please indicate whether during the past 12 months you have suffered from chronic bronchitis, chronic obstructive pulmonary disease or emphysema?"; heart conditions were assessed by two questions, namely, "Please indicate whether during the past 12 months you have suffered from a myocardial infarction (or heart attack) or from the chronic consequences of a myocardial infarction?" and "Please indicate whether during the past 12 months you have suffered from coronary heart disease or angina pectoris?"; diabetes mellitus was defined by an affirmative answer to the question "Please indicate whether during the last 12 months you suffered from diabetes, excluding diabetes during pregnancy?"; obesity was defined as a body mass index (BMI) $\geq 30 \mathrm{~kg} / \mathrm{m}^{2}$ calculated by the formula BMI = weight $(\mathrm{kg}) /[$ height $(\mathrm{m}) \times$ height $(\mathrm{m})$ ]; smoking status was assumed in the individuals that stated they smoke either daily or occasionally.

Self-reported health status was assessed by the question "In general, how do you consider your health condition? (very good/good/fair/bad/very bad)".

Functional capacity was evaluated by the question "To what extent do you feel limited to carry out activities considered usual for most people, due to a health problem? (severely limited/limited but not severely/not limited)".

Regarding access to care, information about healthcare appointments, in the previous 12 months, with a general practitioner (GP), other medical specialists, psychologist, psychotherapist, or psychiatrist was also collected.

Collected sociodemographic factors included sex, age group, living arrangements, educational level, household income, and the distribution of the participants among the seven Portuguese regions classified by the Nomenclature of Territorial Units for Statistics Level 2.

\subsection{Statistical Analysis}

Statistical analyses were performed using SPSS ${ }^{\circledR}$ Statistics (version 27.0; SPSS Inc., Chicago, IL, USA) and Jamovi software (datalab.CC, Sydney, Australia). Categorical variables were described by the absolute and relative frequencies, $n(\%)$. The associations between categorical variables were verified by chi-square tests, and the respective effect size was given by the phi coefficient (effect sizes of 0.1 are considered small, 0.3 medium, and above 0.5 large). Multiple logistic regression models were constructed to access the potential variables associated with multimorbidity. The independent variables to include in multiple regression were chosen by performing simple logistic regressions with the variables in the dataset. All variables that correlated with the outcomes at $p \leq 0.20$ in the simple regression were included in the multiple logistic regression analyses (initial model), and then the variables were removed, one by one, in descending order of the $p$-value, until only those variables with $p$-values $\leq 0.05$ were maintained (final model). The odds ratio $(\mathrm{EXP}(\mathrm{B}))$ with the respective $95 \%$ confidence interval $(95 \% \mathrm{CI})$ and the $p$-value for each variable are provided. The Hosmer-Lemeshow test was the statistical test used to assess the goodness of fit of the final logistic regression model.

Values of $p \leq 0.05$ were considered significant. 


\section{Results}

The inclusion sample consisted of 7859 adult residents in Portugal who had at least one chronic condition. Table 1 provides a summary of the sample characteristics. Approximately sixty-one percent of chronic adult individuals were women. The majority were 65 years or older $(51.1 \%)$, lived with someone $(69.1 \%)$, and had a basic educational level $(62.2 \%)$. One in four individuals reported having a bad to very bad health status, and almost half of the sample (49.1\%) reported being limited or severely limited to carrying out activities considered usual for most people. Considering access to care, the time elapsed since the last doctor appointment (GP or another medical specialist) was less than one year ago for most of the sample. In contrast, an appointment with a psychologist, psychotherapist, or psychiatrist was more uncommon.

Table 1. Characteristics of the chronic adult individuals in the sample $(n=7859)$.

\begin{tabular}{|c|c|}
\hline & $n(\%)$ \\
\hline Sex, women & $4760(60.6)$ \\
\hline \multicolumn{2}{|l|}{ Age groups (years) } \\
\hline$<65$ & $3846(48.9)$ \\
\hline $65+$ & $4013(51.1)$ \\
\hline \multicolumn{2}{|l|}{ Living arrangements } \\
\hline Alone & $2429(30.9)$ \\
\hline With someone & $5430(69.1)$ \\
\hline \multicolumn{2}{|l|}{ Educational level } \\
\hline None & $1134(14.4)$ \\
\hline Basic education (1st, 2nd, and 3rd levels) & $4890(62.2)$ \\
\hline Secondary education & $871(11.1)$ \\
\hline Higher education & $964(12.3)$ \\
\hline \multicolumn{2}{|l|}{ Household Income } \\
\hline 1st quintile & $1421(18.1)$ \\
\hline 2nd quintile & $2298(29.2)$ \\
\hline 3rd quintile & $1737(22.1)$ \\
\hline 4th quintile & $1234(15.7)$ \\
\hline 5 th quintile & $1169(14.9)$ \\
\hline \multicolumn{2}{|l|}{ Regions } \\
\hline North & $1120(14.3)$ \\
\hline Central & $1486(18.9)$ \\
\hline Lisbon and the Tagus Valley & $1230(15.7)$ \\
\hline Alentejo & $1159(14.7)$ \\
\hline Algarve & $787(10.0)$ \\
\hline Madeira & $1126(14.3)$ \\
\hline Azores & $951(12.1)$ \\
\hline \multicolumn{2}{|l|}{ Medical conditions } \\
\hline Chronic kidney disease & $735(9.4)$ \\
\hline COPD & $846(10.8)$ \\
\hline Heart conditions & $882(11.2)$ \\
\hline Obesity & $1822(23.2)$ \\
\hline Smoking & $987(12.6)$ \\
\hline Diabetes mellitus & $1737(22.1)$ \\
\hline \multicolumn{2}{|l|}{ Self-reported health status, $n=7854$} \\
\hline "Bad to Very Bad" Health & $2018(25.7)$ \\
\hline \multicolumn{2}{|l|}{ Functional capacity, $n=7834$} \\
\hline Limited and severely limited & $3848(49.1)$ \\
\hline \multicolumn{2}{|l|}{ Healthcare appointments (previous 12 months) } \\
\hline With GPs, $n=7854$ & $6699(85.3)$ \\
\hline With other medical specialists, $n=7852$ & $4548(57.9)$ \\
\hline With psychologist, psychotherapist, or psychiatrist, $n=7846$ & $1289(16.4)$ \\
\hline
\end{tabular}


Regarding the conditions that increase the risk of severe COVID-19, the most frequently stated conditions were obesity (23.2\%) and diabetes mellitus (22.1\%) (Table 1). Multimorbidity of underlying conditions that increase the risk of severe COVID-19 was present in 1714 individuals (21.8\% of the sample), and $38.4 \%$ had one condition that increases the risk of severe COVID-19 (Table 2).

Table 2. Prevalence of medical conditions that increase a person's risk of severe COVID-19 $(n=7859)$.

\begin{tabular}{|c|c|c|c|c|}
\hline & \multicolumn{3}{|c|}{$\begin{array}{c}\text { Presence of Medical Conditions That Increase a Person's } \\
\text { Risk of Severe COVID-19, } n(\%)\end{array}$} & \multirow[b]{2}{*}{$p$-Value ${ }^{\text {a }}$; Effect Size } \\
\hline & $\begin{array}{c}0 \text { Conditions } \\
(n=3128 ; 39.8 \%)\end{array}$ & $\begin{array}{c}1 \text { Condition } \\
(n=3017 ; 38.4 \%)\end{array}$ & $\begin{array}{c}\geq 2 \text { Conditions } \\
(n=1714 ; 21.8 \%)\end{array}$ & \\
\hline \multicolumn{5}{|l|}{ Sex } \\
\hline Men & $1094(35.3)$ & $1297(41.9)$ & $708(22.8)$ & \multirow[t]{2}{*}{$<0.001 ; 0.08$} \\
\hline Women & $2034(42.7)$ & $1720(36.1)$ & $1006(21.1)$ & \\
\hline \multicolumn{5}{|l|}{ Age groups (years) } \\
\hline$<65$ years & $1692(44.0)$ & $1475(38.4)$ & $679(17.7)$ & \multirow{2}{*}{$<0.001 ; 0.11$} \\
\hline $65+$ years & $1436(35.8)$ & $1542(38.4)$ & $1035(25.8)$ & \\
\hline \multicolumn{5}{|l|}{ Living arrangements } \\
\hline Alone & $885(36.4)$ & $976(40.2)$ & $568(23.4)$ & \multirow[t]{2}{*}{$<0.001 ; 0.05$} \\
\hline With someone & $2243(41.3)$ & $2041(37.6)$ & $1146(21.1)$ & \\
\hline \multicolumn{5}{|l|}{ Educational level } \\
\hline None & $382(33.7)$ & $425(37.5)$ & $327(28.8)$ & \multirow{4}{*}{$<0.001 ; 0.17$} \\
\hline Basic education (1st, 2nd, and 3rd levels) & $1793(36.7)$ & $1907(39.0)$ & $1190(24.3)$ & \\
\hline Secondary education & $434(49.8)$ & $345(39.6)$ & $92(10.6)$ & \\
\hline Higher education & $519(53.8)$ & $340(35.3)$ & $105(10.9)$ & \\
\hline \multicolumn{5}{|l|}{ Household income } \\
\hline 1st quintile & $515(36.2)$ & $565(39.8)$ & $341(24.0)$ & \multirow{5}{*}{$<0.001 ; 0.11$} \\
\hline 2nd quintile & $878(38.2)$ & $877(38.2)$ & $543(23.6)$ & \\
\hline 3rd quintile & $627(36.1)$ & $664(38.2)$ & $446(25.7)$ & \\
\hline 4th quintile & $546(44.2)$ & $462(37.4)$ & $226(18.3)$ & \\
\hline 5th quintile & $562(48.1)$ & $449(38.4)$ & $158(13.5)$ & \\
\hline \multicolumn{5}{|l|}{ Regions } \\
\hline North & $448(40.0)$ & $449(40.1)$ & $223(19.9)$ & \multirow{7}{*}{$<0.001 ; 0.07$} \\
\hline Central & $643(43.3)$ & $526(35.4)$ & $317(21.3)$ & \\
\hline Lisbon and the Tagus Valley & $492(40.0)$ & $480(39.0)$ & $258(21.0)$ & \\
\hline Alentejo & $452(39.0)$ & $455(39.3)$ & $252(21.7)$ & \\
\hline Algarve & $329(41.8)$ & $302(38.4)$ & $156(19.8)$ & \\
\hline Madeira & $448(39.8)$ & $423(37.6)$ & $255(22.6)$ & \\
\hline Azores & $316(33.2)$ & $382(40.2)$ & $253(26.6)$ & \\
\hline \multicolumn{5}{|l|}{ Self-reported health status } \\
\hline Very good & $106(55.8)$ & $73(38.4)$ & $11(5.8)$ & \multirow{5}{*}{$<0.001 ; 0.25$} \\
\hline Good & $835(51.9)$ & $610(37.9)$ & $165(10.2)$ & \\
\hline Fair & $1630(40.4)$ & $1588(39.3)$ & $818(20.3)$ & \\
\hline Bad & $443(28.7)$ & $585(37.9)$ & $517(33.5)$ & \\
\hline Very bad & $112(23.7)$ & $158(33.4)$ & $203(42.9)$ & \\
\hline \multicolumn{5}{|l|}{ Functional capacity } \\
\hline Severely limited & $242(25.2)$ & $357(37.1)$ & $363(37.7)$ & \multirow{3}{*}{$<0.001 ; 0.21$} \\
\hline Limited but not severely & $1016(35.2)$ & $1096(38.0)$ & $774(26.8)$ & \\
\hline Not limited & $1855(46.5)$ & $1555(39.0)$ & $576(14.5)$ & \\
\hline \multicolumn{5}{|l|}{ Healthcare appointments } \\
\hline With GPs, $n=7854$ & & & & \multirow{3}{*}{$<0.001 ; 0.07$} \\
\hline$<12$ months & $2598(38.8)$ & $2561(38.2)$ & $1540(23.0)$ & \\
\hline$\geq 12$ months or never & $528(45.7)$ & $454(39.3)$ & $173(15.0)$ & \\
\hline \multicolumn{5}{|l|}{ With other medical specialists, $n=7852$} \\
\hline$<12$ months & $1750(38.5)$ & 1709 (37.6) & $1089(23.9)$ & \multirow[t]{2}{*}{$<0.001 ; 0.06$} \\
\hline$\geq 12$ months or never & $1377(41.7)$ & $1304(39.5)$ & $623(18.9)$ & \\
\hline
\end{tabular}


Table 2. Cont.

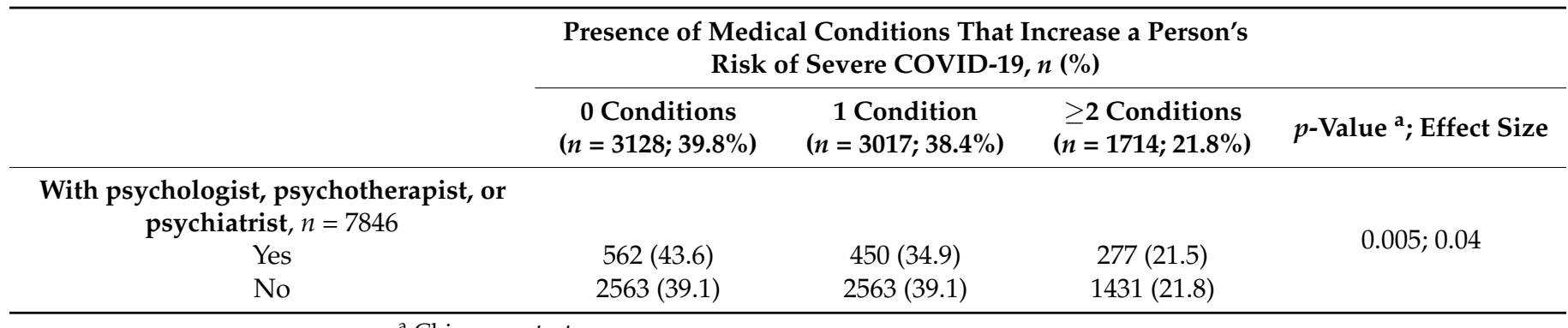

${ }^{\text {a }}$ Chi-square test.

As shown in Table 2, the prevalence of one or more medical conditions that increase a person's risk of severe COVID-19 was $64.7 \%$ for men and $57.2 \%$ for women. The prevalence of $\geq 1$ conditions was also high in individuals aged 65 and older (64.2\%), living alone $(63.6 \%)$, and having no education $(66.3 \%)$ or a basic educational level $(63.3 \%)$, and in households in the lower-income quintiles: first quintile $(63.8 \%)$, second quintile $(61.8 \%)$, and third quintile $(63.9 \%)$. High frequencies of one or more medical conditions that increase a person's risk of severe COVID-19 were also associated with worse self-reported health status and lower functionality (Table 2).

Table 3 shows that in chronic adult individuals, multimorbidity of underlying conditions that increase the risk of severe COVID-19 is less likely to occur in women, in individuals with higher educational levels, in those with higher functionality, and in those who had a medical appointment less than one year ago. In contrast, the odds of multimorbidity increased in individuals living in the region of Madeira and Azores, and in those with a poor self-reported health status (Hosmer-Lemeshow test: $p$-value $=0.425$ ).

Table 3. Multiple logistic regression model for demographic and clinical variables associated with multimorbidity of underlying conditions that increase the risk of severe COVID-19.

\begin{tabular}{|c|c|c|c|c|}
\hline & \multicolumn{2}{|c|}{ Initial Model } & \multicolumn{2}{|c|}{ Final Model } \\
\hline & $\begin{array}{c}\mathrm{EXP}(\mathrm{B}) \\
{[95 \% \mathrm{CI}]}\end{array}$ & $p$-Value & $\begin{array}{l}\text { EXP(B) } \\
{[95 \% \text { CI }]}\end{array}$ & $p$-Value \\
\hline Sex & \multirow{2}{*}{\multicolumn{2}{|c|}{ Reference }} & \\
\hline Men & & & Referen & \\
\hline $\begin{array}{l}\text { Women } \\
\text { Age }\end{array}$ & \multicolumn{3}{|c|}{ Age } & $<0.001$ \\
\hline$<65$ years & \multicolumn{2}{|c|}{ Reference } & & \\
\hline $65+$ years & $1.10[0.96 ; 1.25]$ & 0.159 & & \\
\hline \multicolumn{5}{|l|}{ Living arrangements } \\
\hline With someone & \multicolumn{2}{|c|}{ Reference } & & \\
\hline Alone & $1.05[0.93 ; 1.20]$ & 0.418 & & \\
\hline \multicolumn{5}{|l|}{ Education level } \\
\hline None & \multicolumn{2}{|c|}{ Reference } & \multicolumn{2}{|c|}{ Reference } \\
\hline $\begin{array}{c}\text { Basic education (1st, 2nd, and } \\
\text { 3rd levels) }\end{array}$ & $0.99[0.84 ; 1.16]$ & 0.859 & $0.98[0.84 ; 1.14]$ & 0.755 \\
\hline Secondary education & $0.53[0.40 ; 0.70]$ & $<0.001$ & $0.50[0.38 ; 0.66]$ & $<0.001$ \\
\hline Higher education & $0.56[0.41 ; 0.77]$ & $<0.001$ & $0.54[0.42 ; 0.70]$ & $<0.001$ \\
\hline \multicolumn{5}{|l|}{ Household Income } \\
\hline 1st quintile & \multicolumn{2}{|c|}{ Reference } & & \\
\hline 2nd quintile & $0.89[0.74 ; 1.05]$ & 0.164 & & \\
\hline 3rd quintile & $1.10[0.92 ; 1.32]$ & 0.295 & & \\
\hline 4th quintile & $0.95[0.77 ; 1.16]$ & 0.594 & & \\
\hline 5th quintile & $0.95[0.73 ; 1.24]$ & 0.717 & & \\
\hline
\end{tabular}


Table 3. Cont.

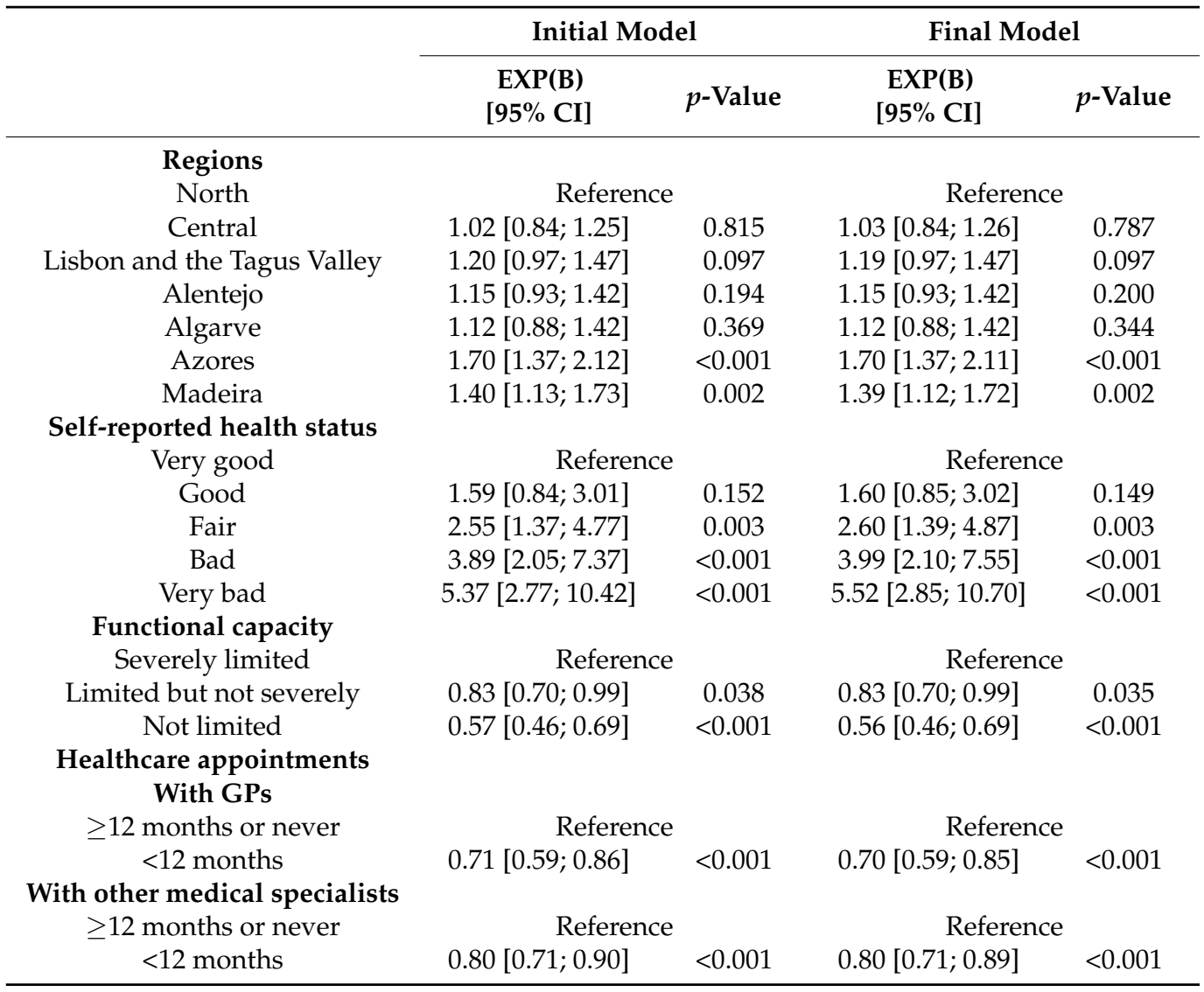

\section{Discussion}

This is the first national study of multimorbidity of underlying conditions that increase the risk of severe COVID-19 in Portugal using the most recent Portuguese National Health Survey 2019. The present analysis shows that, in Portugal, approximately 6 out of every 10 individuals with chronic diseases suffer from one or more conditions that are on the list of those at increased risk of severe COVID-19 disease. This observed high prevalence was not unexpected. It was previously suggested that $22 \%$ of individuals worldwide may be at increased risk of severe COVID-19 [8], and in Portugal, 15.5\% of the population might be at high risk for complications from COVID-19 according to the 2014 Portuguese National Health Interview Survey [24]; therefore, it is likely that higher frequencies will be found in chronic adult individuals, as is the case of the population of the present study.

Another possible explanation for these epidemiological differences is that not all studies used the same list of risk factors for severe COVID-19 disease. For example, one study conducted in the US found that more than $75 \%$ of adults would be at increased risk of severe COVID-19 by using a predefined list of ten medical conditions [25], and another study, performed in Brazil, that used a list of nine conditions observed that more than half of the population in São Paulo city had at least one risk factor for severe COVID-19 [26]. Nonetheless, the present study employed a list of the most common conditions that are closely linked to COVID-19 severity, including cardiovascular diseases, diabetes, chronic kidney diseases, and chronic respiratory diseases [8]. It can therefore be assumed that more than half of the chronic patients in Portugal, if infected by the SARS-CoV-2 virus, may be at high risk of hospitalization, admission to an ICU, intubation or mechanical ventilation, and/or death by CDC criteria [7].

Regarding multimorbidity of underlying conditions that increase the risk of severe COVID-19, it was present in $21.8 \%$ of the study population, with a male predominance $(p<0.001)$. This may suggest that, in Portugal, approximately 2 out of every 10 individuals 
with chronic diseases are at increased risk of premature death attributed to COVID-19, considering the already known association between multimorbidity and mortality by COVID-19 [19,20,27-29].

However, while some of these epidemiological findings have been previously recognized [8,24], other aspects relating to multimorbidity and COVID-19 addressed in the present study are new or less well described, and, at the same time, they answer to previously identified gaps in the research [18], such as considering not only underlying conditions but also sociodemographic factors [8] and clinical characteristics.

Data from a previous nationwide representative study showed that multimorbidity in Portugal is more prevalent in women, individuals who are older, and those with lower educational levels [30]. This differs from the findings of the present study, in which women were less likely to suffer from multimorbidity of underlying conditions that increase the risk of severe COVID-19, and no differences were found by age, living arrangements, or household income in the multiple model. These results are consistent with data obtained in a recent literature review of twenty-eight COVID-19 and multimorbidity publications [19], which showed a higher probability of death in hospitalized men with COVID-19 and a similar increased risk of death from COVID-19 in multimorbid patients aged either below or above 65 compared to those without comorbidities [19].

Education is an undeniable social determinant of health with a robust association with life expectancy, illness, and health behaviors [31]. Therefore, it comes as no surprise that in the present study, the odds of multimorbidity decreased in individuals with higher educational levels. This finding suggests that in the post-COVID-19 era, the importance of education must not be overlooked, and the interlude to education must come to an end when pandemic limitations are reduced or abolished.

Multimorbidity of underlying conditions that increase the risk of severe COVID-19 was more likely to occur in chronic adult individuals with a poor self-reported health status, but not in those with higher functionality or who had a medical appointment less than one year ago. The present data do not allow for further justification, but it is possible that, because of their health conditions (and thus poor self-reported health status), low functionality, and lack of regular medical follow-up, this population is more vulnerable to severe COVID-19 in cases of infection. This may also be the case for those living in the archipelago of Azores and Madeira due to the lack of physicians (GPs or other medical specialists) in some locations. The current data do not allow us to prove or refute these hypotheses.

There are some limitations to this research. As with previous studies, the use of self-reported medical data may underestimate the prevalence of risk factors for severe COVID-19 [32,33]. Another limitation was the use of conditions defined by the CDC as posing a risk for severe COVID-19 and available in the INS 2019 study's database, which may influence the frequency of multimorbidity because of the number of conditions used [34]. Additionally, INS 2019 does not allow for the determination of the severity of the underlying conditions, which may impact the effect size of each risk factor for severe COVID-19 [19,25]. These limitations are very common in previously published epidemiological studies of severe COVID-19 [25,33,35].

The findings of the current study characterize some of the sociodemographic and clinical variables associated with multimorbidity of underlying conditions that increase the risk of severe COVID-19 in chronic adult individuals and can assist in the definition of strategies of pandemic management, including addressing some health inequalities [36].

\section{Conclusions}

In Portugal, approximately 6 out of every 10 individuals with chronic diseases suffer from one or more conditions that are on the list of those at increased risk of severe COVID19 disease, and approximately 2 out of every 10 individuals have multimorbidity (two or more of these conditions). Obesity and diabetes are the most frequent risk factors.

Timely interventions (e.g., regular medical follow-up for preventive health services and health information) targeting multimorbidity in males and individuals with low 
educational levels, a poor health status, and low functionality may help to reduce the risk of severe COVID-19 and post-COVID-19 sequelae, and to improve health in a large proportion of the population.

Author Contributions: Conceptualization, F.P.; methodology, F.P.; formal analysis, A.T. and L.C.; investigation, F.P. and A.T.; data curation, F.P.; writing-original draft preparation, F.P.; writingreview and editing, F.P., L.C., and A.T.; supervision, F.P. All authors have read and agreed to the published version of the manuscript.

Funding: This research received no external funding.

Institutional Review Board Statement: This study was conducted according to the guidelines of the Declaration of Helsinki and approved by the Ethics Committee of the University of Beira Interior (protocol code CE-UBI-Pj-2020-073:ID2190 on 13 October 2020).

Informed Consent Statement: Informed consent was obtained from all subjects involved in the INS 2019.

Data Availability Statement: The data are not publicly available since, due to the nature of this research, there is no authorization for the data to be shared.

Conflicts of Interest: The authors declare no conflict of interest.

\section{References}

1. Worldometer. COVID-19 Coronavirus Pandemic. Available online: https://www.worldometers.info/coronavirus / (accessed on 17 August 2021).

2. DGS. Ponto de Situação Atual em Portugal. Available online: https://covid19.min-saude.pt/ponto-de-situacao-atual-emportugal/ (accessed on 17 August 2021).

3. IHME. COVID-19 Vaccine Efficacy Summary. Available online: http:/ /www.healthdata.org/covid/covid-19-vaccine-efficacysummary (accessed on 17 August 2021).

4. Mathieu, E.; Ritchie, H.; Ortiz-Ospina, E.; Roser, M.; Hasell, J.; Appel, C.; Giattino, C.; Rodes-Guirao, L. A global database of COVID-19 vaccinations. Nat. Hum. Behav. 2021, 5, 947-953. [CrossRef] [PubMed]

5. Our World in Data. Coronavirus (COVID-19) Vaccinations. Available online: https://ourworldindata.org/covid-vaccinations (accessed on 21 August 2021).

6. Del Rio, C.; Malani, P. COVID-19 in 2021-continuing uncertainty. JAMA 2021, 325, 1389-1390. [CrossRef] [PubMed]

7. CDC. Evidence Used to Update the List of Underlying Medical Conditions That Increase a Person's Risk of Severe Illness from COVID-19. Available online: https://www.cdc.gov/coronavirus/2019-ncov/science/science-briefs/underlyingevidence-table.html?CDC_AA_refVal=https\%3A\%2F\%2Fwww.cdc.gov\%2Fcoronavirus\%2F2019-ncov\%2Fhcp \%2Fclinicalcare\%2Funderlying-evidence-table.html (accessed on 3 November 2020).

8. Clark, A.; Jit, M.; Warren-Gash, C.; Guthrie, B.; Wang, H.H.X.; Mercer, S.W.; Sanderson, C.; McKee, M.; Troeger, C.; Ong, K.L.; et al. Global, regional, and national estimates of the population at increased risk of severe COVID-19 due to underlying health conditions in 2020: A modelling study. Lancet Glob. Health 2020, 8, e1003-e1017. [CrossRef]

9. Visco, V.; Vitale, C.; Rispoli, A.; Izzo, C.; Virtuoso, N.; Ferruzzi, G.J.; Santopietro, M.; Melfi, A.; Rusciano, M.R.; Maglio, A.; et al. Post-COVID-19 syndrome: Involvement and interactions between respiratory, cardiovascular and nervous systems. J. Clin. Med. 2022, 11, 524. [CrossRef] [PubMed]

10. Malik, P.; Patel, K.; Pinto, C.; Jaiswal, R.; Tirupathi, R.; Pillai, S.; Patel, U. Post-acute COVID-19 syndrome (PCS) and health-related quality of life (HRQoL)-a systematic review and meta-analysis. J. Med. Virol. 2022, 94, 253-262. [CrossRef] [PubMed]

11. Grasselli, G.; Greco, M.; Zanella, A.; Albano, G.; Antonelli, M.; Bellani, G.; Bonanomi, E.; Cabrini, L.; Carlesso, E.; Castelli, G.; et al. Risk factors associated with mortality among patients with COVID-19 in intensive care units in Lombardy, Italy. JAMA Intern. Med. 2020, 180, 1345-1355. [CrossRef]

12. Atkins, J.L.; Masoli, J.A.H.; Delgado, J.; Pilling, L.C.; Kuo, C.L.; Kuchel, G.A.; Melzer, D. Preexisting comorbidities predicting COVID-19 and mortality in the UK biobank community cohort. J. Gerontol. A Biol. Sci. Med. Sci. 2020, 75, 2224-2230. [CrossRef] [PubMed]

13. Williamson, E.J.; Walker, A.J.; Bhaskaran, K.; Bacon, S.; Bates, C.; Morton, C.E.; Curtis, H.J.; Mehrkar, A.; Evans, D.; Inglesby, P.; et al. Factors associated with COVID-19-related death using OpenSAFELY. Nature 2020, 584, 430-436. [CrossRef]

14. Guan, W.J.; Liang, W.H.; Zhao, Y.; Liang, H.R.; Chen, Z.S.; Li, Y.M.; Liu, X.Q.; Chen, R.C.; Tang, C.L.; Wang, T.; et al. Comorbidity and its impact on 1590 patients with COVID-19 in china: A nationwide analysis. Eur. Respir. J. 2020, 55, 2000547. [CrossRef]

15. Zhang, J.; Wang, X.; Jia, X.; Li, J.; Hu, K.; Chen, G.; Wei, J.; Gong, Z.; Zhou, C.; Yu, H.; et al. Risk factors for disease severity, unimprovement, and mortality in COVID-19 patients in Wuhan, China. Clin. Microbiol. Infect. 2020, 26, 767-772. [CrossRef] 
16. Violan, C.; Foguet-Boreu, Q.; Flores-Mateo, G.; Salisbury, C.; Blom, J.; Freitag, M.; Glynn, L.; Muth, C.; Valderas, J.M. Prevalence, determinants and patterns of multimorbidity in primary care: A systematic review of observational studies. PLoS ONE 2014, 9, e102149. [CrossRef] [PubMed]

17. Prazeres, F.; Santiago, L. Prevalence of multimorbidity in the adult population attending primary care in Portugal: A crosssectional study. BMJ Open 2015, 5, e009287. [CrossRef]

18. Mair, F.S.; Foster, H.M.; Nicholl, B.I. Multimorbidity and the COVID-19 pandemic-An urgent call to action. J. Comorb. 2020, 10, 2235042X20961676. [CrossRef] [PubMed]

19. Tisminetzky, M.; Delude, C.; Hebert, T.; Carr, C.; Goldberg, R.J.; Gurwitz, J.H. Age, multiple chronic conditions, and COVID-19: A literature review. J. Gerontol. A Biol. Sci. Med. Sci. 2020, 75, glaa320. [CrossRef]

20. Iaccarino, G.; Grassi, G.; Borghi, C.; Ferri, C.; Salvetti, M.; Volpe, M.; Investigators, S.-R. Age and multimorbidity predict death among COVID-19 patients: Results of the sars-ras study of the italian society of hypertension. Hypertension 2020, 76, 366-372. [CrossRef] [PubMed]

21. McQueenie, R.; Foster, H.M.E.; Jani, B.D.; Katikireddi, S.V.; Sattar, N.; Pell, J.P.; Ho, F.K.; Niedzwiedz, C.L.; Hastie, C.E.; Anderson, J.; et al. Multimorbidity, polypharmacy, and COVID-19 infection within the UK biobank cohort. PLoS ONE 2020, 15, e0238091. [CrossRef]

22. INE. Inquérito Nacional de Saúde. Available online: https://www.ine.pt/xportal/xmain?xpid=INE\&xpgid=ine_destaques\& DESTAQUESdest_boui=414434213\&DESTAQUESmodo=2 (accessed on 5 August 2021).

23. INE. Inquérito Nacional de Saúde 2019, Código 616/Versão 1-Documento Metodológico; DES/Serviço de Estatísticas das Condições de Vida: Lisboa, Portugal, 2019.

24. Laires, P.A.; Nunes, C. Population-based estimates for high risk of severe COVID-19 disease due to age and underlying health conditions. Acta Med. Port. 2020, 33, 720-725. [CrossRef]

25. Ajufo, E.; Rao, S.; Navar, A.M.; Pandey, A.; Ayers, C.R.; Khera, A.U.S. Population at increased risk of severe illness from COVID-19. Am. J. Prev. Cardiol. 2021, 6, 100156. [CrossRef]

26. Thome, B.; Rezende, L.F.M.; Schveitzer, M.C.; Monteiro, C.N.; Goldbaum, M. Differences in the prevalence of risk factors for severe COVID-19 across regions of Sao Paulo city. Rev. Bras. Epidemiol. 2020, 23, e200087. [CrossRef]

27. Hanlon, P.; Chadwick, F.; Shah, A.; Wood, R.; Minton, J.; McCartney, G.; Fischbacher, C.; Mair, F.S.; Husmeier, D.; Matthiopoulos, J.; et al. COVID-19-Exploring the implications of long-term condition type and extent of multimorbidity on years of life lost: A modelling study. Wellcome Open Res. 2020, 5, 75. [CrossRef]

28. Ecks, S. Multimorbidity, polyiatrogenesis, and COVID-19. Med. Anthropol. Q. 2020, 34, 488-503. [CrossRef]

29. Aoun, M.; Khalil, R.; Mahfoud, W.; Fatfat, H.; Bou Khalil, L.; Alameddine, R.; Afiouni, N.; Ibrahim, I.; Hassan, M.; Zarzour, H.; et al. Age and multimorbidities as poor prognostic factors for COVID-19 in hemodialysis: A Lebanese national study. BMC Nephrol. 2021, 22, 73. [CrossRef] [PubMed]

30. Quinaz Romana, G.; Kislaya, I.; Salvador, M.R.; Cunha Goncalves, S.; Nunes, B.; Dias, C. Multimorbidity in Portugal: Results from the first national health examination survey. Acta Med. Port. 2019, 32, 30-37. [CrossRef] [PubMed]

31. The Lancet Public Health. Education: A neglected social determinant of health. Lancet Public Health 2020, 5, e361. [CrossRef]

32. Rezende, L.F.M.; Thome, B.; Schveitzer, M.C.; Souza-Junior, P.R.B.; Szwarcwald, C.L. Adults at high-risk of severe coronavirus disease-2019 (COVID-19) in Brazil. Rev. Saude Publica 2020, 54, 50. [CrossRef]

33. Li, H.L.; Cheung, B.M.Y. The proportion of adult Americans at risk of severe COVID-19 illness. J. Gen. Intern. Med. 2021, 36, 259-261. [CrossRef]

34. Prazeres, F.; Santiago, L. Measuring multimorbidity in family practice-a comparison of two methods. Fam. Pract. 2018, 35, 571-575. [CrossRef]

35. Nunes, B.P.; Souza, A.S.S.; Nogueira, J.; Andrade, F.B.; Thume, E.; Teixeira, D.; Lima-Costa, M.F.; Facchini, L.A.; Batista, S.R. Multimorbidity and population at risk for severe COVID-19 in the Brazilian longitudinal study of aging. Cad. Saude Publica 2020, 36, e00129620. [CrossRef]

36. Shaaban, A.N.; Peleteiro, B.; Martins, M.R.O. COVID-19: What is next for Portugal? Front. Public Health 2020, 8, 392. [CrossRef] 